\title{
ANALISIS PERHITUNGAN DAN PEMOTONGAN PAJAK PENGHASILAN PASAL 21 PADA KARYAWAN TETAP PT. AIR MANADO
}

\author{
Risna Latif ${ }^{1}$, Harijanto Sabijono ${ }^{2}$, Dhullo Afandi $^{3}$ \\ 1,2,3 Jurusan Akuntansi, Fakultas Ekonomi dan Bisnis, Universitas Sam Ratulangi, Jln. Kampus Bahu, Manado \\ 95115, Indonesia \\ E-mail : risnalatif82964@gmail.com
}

\begin{abstract}
Income Tax Article 21, or commonly referred to Article 21 Income Tax is as tax on incomce in the form of wages, salary, honoraria, allowances and other payments to the name and in any form in connection with employment or occupation, services and activities that carried out by private persons subject to tax in the country. the purpose of this research is to analyse whether the application of calculation and deduction of Article 21 income tax at PT. Air in Manado has already met the rule of taxing. The method used in this research is descriptive analysis method, object study was conducted at the PT. Air Manado. Based on thediscussion of research results, it was concluded that in determining the calculation and deduction of Article 21 Income Tax at PT. Air Manado is still not in accordance with the latest tax regulations.
\end{abstract}

Keywords : Article 21 Income Tax

\section{PENDAHULUAN}

Jadi tiap pegawai/karyawan yang bekerja pasti akan mengdapat penghasilan pekerjaanya tersebut. Dan juga pegawai/karyawan yang bekerja disebuah instansi/perusahaan, pastinya juga akan ada penghasilan yang biasanya disebut gaji/upah. Dari penghasilan yang diterima pegawai/karyawan pemerintah akan menarik pajak atas penghasilan pegawai/karyawan tersebut. Jenis pajak di Indonesia sekarang dibagi menjadi dua, yaitu Pajak Pusat dan Pajak Daerah. Salah satu Pajak Daerah adalah Pajak Penghasilan. Pajak Penghasilan 21 menurut Undang-Undang No. 36 Tahun 2008 tentang Pajak Penghasilan adalah pajak atas penghasilan berupa gaji, upah, honorarium, tunjangan, dan pembayaran lain dengan nama dan dalam bentuk apapun sehubungan dengan pekerjaan atau jabatan, jasa, dan kegiatanyang dilakukan oleh orang pribadi dalam negeri.

Kewajiban PPh 21 yaitu wajib pajak (penerima penghasilan) wajib pajak menyerahkan surat pernyataan kepada pemotong pajak, yang menyatakan jumlah tanggungan keluarga pada suatu tahun takwim untuk mendapatkan pengurangan berupa Penghasilan Tidak Kena Pajak (PTKP). Wajib pajak berkewajiban menyerahkan SPT tahunan wajib pajak orang pribadi, jika wajib pajak mempunyai penghasilan lebih dari satu pemberi kerja. Berpihak berkewajiban melakukan pemotongan, menyetor, dan melaporkan PPh Pasal 21.

\section{TINJAUAN PUSTAKA}

Pemotongan Pajak Penghasilan Pasal 21. Pemotongan Pajak Penghasilan 21 adalah : "Wajib Pajak orang pribadi atau Wajib Pajak badan, termasuk bentuk usaha tetap, yang mempunyai kewajiban untuk melakukan pemotongan pajak atas penghasilan sehubungan dengan pekerjaan, jasa, dan kegiatan orang pribadi sebagaimana dimaksud dalam Pasal 21 undang-undang pajak penghasilan”. 
Tabel 1. Tarif Pajak Untuk Wajib Pajak Orang Pribadi dalam Negeri

\section{Lapisan Penghasilan Kena Pajak}

Sampai dengan Rp 50.000.000,00

Diatas Rp 50.000.000,00 s.d Rp 250.000.000,00

Diatas Rp 250.000.000,00 s.d Rp 500.000.000,00

Diatas Rp 500.000.000,00
Tarif Pajak

$5 \%$

$15 \%$

$25 \%$

$30 \%$

Sumber : UU No. 36 Tahun 2008

Pajak Penghasilan Pasal 21. Mardiasmo (2013:188) : “menyatakan Pajak Penghasilan pasal 21 ialah pajak mengatasi penghasiilan seperti gaaji, upaah, honorariium, tunjanggan dan pmbayaran lainnya denggan nama dan dalam bentuk apapun sehubungan dengan kerjaan atau jabattan, jasaa dan kegiatana yangg melakukan diperoleh orrang pribadi”.

Penghasilan Tidak Kena Pajak (PTKP). "Peraturan Menteri Keuangan Republik Indonesia Nomor 162/PMK.011/2012 tanggal 22 Oktober 2012 tentang penyesuian besarnya penghasilan tidak kena pajak digantikan dengan peraturan pemeriintah baru yaitu Peraturan Menteri Keuangan Nomor 122/PMK.010/2015 mengenai tarif penyesuian besarnya penghasilan tidak kena pajak (PTKP) tahun 2015 dan juga digantikan dengan peraturan perundang-perundangan baru Nomor 101/PMK.010/2016 tentang besarnya Penghasilan Tidak Kena Pajak (PTKP) tahun 2016”.

\section{Penelitian Terdahulu}

1. Angelia Friska Makabimbang (2013) dengan "judul Analisis Perhitungan, Pembayaran dan Pelapaporan PPh Pasal 21 pada Dinas Pendidikan Kecamatan Tuminting. Tujuan Penelitian yaitu untuk mengetahui bagaimana proses perhitungan dan pembayaran dan pelaporan pajak penghasilan pasal 21 pada pegawai dinas pendidikan kecamatan tuminting. Metode penelitian adalah deskriptif. Hasil pemabahasan yaitu perhitungan, pembayaran dan pelaporan telah sesuai dengan undang-undang yang berlaku. Persamaan yaitu membandingkan perhitungan dan pemotongan $\mathrm{PPh}$ Pasal 21 apakah telah sesuai dengan peraturan perpajakan yang berlaku. Perbedaan adalah menjabarkan proses pembayaran dan pelaporan pajak $\mathrm{PPh}$ pasal 21 sedangkan penelitian ini tidak melakukan".

2. Stien Selvie (2016) dengan "judul Evaluasi Perhitungan, Penyetoran dan Pelaporan Pajak Penghasilan Pasal 21 bagi pegawai tetap. Tujuan Penelitian yaitu untuk mengetahui perhitungan, penyetoran dan pelaporan pajak PPh Pasal 21 pada pegawai tetap Feb Unsrat. Metode penelitian adalah kualitatif interpretif. Hasil pemabahasan yaitu perhitungan, pembayaran dan pelaporan telah sesuai dengan undang-undang yang berlaku. Persamaan yaitu membandingkan perhitungan dan pemotongan $\mathrm{PPh}$ Pasal 21 apakah telah sesuai dengan peraturan perpajakan yang berlaku. Perbedaan adalah menjabarkan proses pembayaran dan pelaporan pajak $\mathrm{PPh}$ pasal 21 sedangkan penelitian ini tidak melakukan"

\section{METODE PENELITIAN}

Jenis penelitian. Penelitian ini menggunakan penelitian kualitatif deskriptif analisis yaitu pendekatan studi kasus yang tujuannya memberikan gambar didalam keadaan perusahaan dengan dilakukannya kegiatan wawancara atau dokumentasi.

Tempat Penelitian. Penelitian dilakukan pada PT. Air Manado, di jln. Yos Sudarso No. 33b, Paal dua, Kota Manado, Sulawesi Utara, Indonesia.

Jenis dan Sumber Data. Penelitian ini mengunakan metode kualitatif. Metode kualitatif merupakan data yan disajkan secara deskriptif atau badan dalam bentuk urain misalnya profil perusahaan. "Data primer yaitu data yang dikumpulkan sendiri oleh perseorangan atau suatu 
organisasi langsung melalui objeknya membutuhkan pengolahan lebih lanjut. Data ini berupa hasil wawancara guna mendapatkan jawaban atas permasalahan yang diteliti. Data sekunder yaitu data yang diperoleh dalam bentuk yang sudah jadi berupa publikasi. Data ini berupa sejarah singkat dan struktur organisasi perusahaan dan sebagainya”.

Teknik Pengumpulan Data. Teknik pengumpulan data yang digunakan dalam peneilitian, adalah: (1) Wawancara; dan (2) Dokumentasi

Metode Analisis. Penelitian ini merupakan penelitian yang bersifat deskriptif, yaitu menganalisis Perhitungan Penghasilan Tidak Kenak Pajak (PTKP) dan Pemotongan Karyawan PT. Air Manado. Dalam analisis ini dengan keterbatasan data dan waktu maka analisis ini hanya menggunakan data berhubungan dengan pajak penghasilan Karyawan bulan Januari-Desember 2016.

Proses Analisis. Hal utama yang akan dibahas dalam analisis ini, yaitu:

1. Mempelajari dan mengumpulkan dokumen atau data yang digunakan dalam perhitungan Pajak Penghasilan Pasal 21

2. Mempelajari prosedur apa saja yaang dilakukan dalam perhitungan diatas Pajak Penghasilan Pasal 21

3. Membandingkan dan menganalisa perhitungan Pajak Penghasilan karyawan pada kantor PT. Air Manado apakah sesua atau tidak dengan UU perpajakan yang berlaku

4. Menguji perhitungan laporan selama bulan Januari-Desember 2016

5. Mengidentifikasi objek pajak penghasilan pasal 21

\section{HASIL PENELITIAN DAN PEMBAHASAN}

\subsection{Hasil Penelitian}

Air Manado adalah "sistem penyediaan air minum kota manado (zaman belanda) dengan nama dinas air minum yang dioperasikan langsung oleh Pemda Kotamadya Manado Tahun 1976, perusahaan air minum dibentuk melalui Perda No. 1/Perda/WKDM/1976 Tanggal 9 Februari 1976, Tahun 1977, disahkan oleh Gubernur kepala Daerah tingkat 1 Sulawesi Utaradengan surat keputusan Nomor 6 Tahun 1977 tanggal 12 Januari 1997.

Dan lebih diatur lagi dengan Surat Keputusan Walikota Manado No. 55 Tahun 2001, Tanggal 1 Maret 2001. Tahun 2005, tanggal 22 Oktober 2005, Penandatanganan Kontrak kerjasama antara PDAM/Pemkot Manado dengan WMD Belanda. Tahun 2007 tanggal 15 Januari 2007, Peresmian beroperasinya PT. AIR MANADO”.

Tabel 2. Perhitungan PPh Pasal 21

1. Nama : J.K (K/1)

\begin{tabular}{lr}
\hline \multicolumn{1}{c}{ Penghasilan dan Pemotongan PPh Pasal 21 } & Rp \\
\hline Penghasilan Bruto & 52.000 .000 \\
Pengurangan: & 520.000 \\
BPJS 1\% & 1.040 .000 \\
Iuran Pensiun 2\% & 2.600 .000 \\
Biaya Jabatan 5\% & 4.160 .000 \\
Jumlah Pengurangan & \\
Jumlah Penghasilan Neto (1) & 47.840 .000 \\
\cline { 2 - 2 } Penghasilan Tidak Kena Pajak: & \\
Wajib pajak orang pribadi & \\
Wajib Pajak Kawin & \\
Tanggungan Anak 1 & \\
Jumlah Penghasilan Tidak Kena Pajak (2) & 4.500 .0000 \\
Penghasilan Kena Pajak (1-2) & 4.500 .000 \\
\hline
\end{tabular}

Sumber: Data SPT Tahunan PT. Air Manado 2017 
Berdasarkan hasil perhitungan Pajak Penghasilan Pasal 21 diatas pada tabel 4 bisa dilihat bahwa penghasilan neto Bapak J.T sebesar Rp. 47.840 .000 setahun adalah total seluruh penghasilan dan tunjangan-tunjangan yang dikurangi iuran wajib pegawai, kemudian penghasilan tersebut dikurangi PTKP sehingga menghasilkan Penghasilan Kena Pajak (PKP).

2. Nama : R.L (K/3)

\begin{tabular}{|c|c|}
\hline Penghasilan dan Pemotongan PPh Pasal 21 & $\mathbf{R p}$ \\
\hline Penghasilan Bruto & 45.000 .000 \\
\hline \multicolumn{2}{|l|}{ Pengurangan: } \\
\hline BPJS $1 \%$ & 450.000 \\
\hline Iuran Pensiun 2\% & 900.000 \\
\hline Biaya Jabatan 5\% & 2.250 .000 \\
\hline Jumlah Pengurangan & 3.600 .000 \\
\hline Jumlah Penghasilan Neto (1) & 41.400 .000 \\
\hline \multicolumn{2}{|l|}{ Penghasilan Tidak Kena Pajak: } \\
\hline Wajib pajak orang pribadi & 54.000 .000 \\
\hline Wajib Pajak Kawin & 4.500 .000 \\
\hline Tanggungan Anak 3 & 13.500 .000 \\
\hline Jumlah Penghasilan Tidak Kena Pajak (2) & 72.000 .000 \\
\hline Penghasilan Kena Pajak (1-2) & NIHIL \\
\hline
\end{tabular}

Sumber: Data SPT Tahunan PT. Air Manado 2017

Berdasarkan hasil perhitungan Pajak Penghasilan Pasal 21 diatas pada tabel 5 bisa dilihat juga bahwa penghasilan neto Bapak R.L sebesar Rp. 41.400 .000 setahun adalah total seluruh penghasilan dan tunjangan-tunjangan yang dikurangi iuran wajib pegawai, kemudian penghasilan tersebut dikurangi PTKP sehingga menghasilkan Penghasilan Kena Pajak (PKP).

\begin{tabular}{|c|c|}
\hline 3. Nama : J.V.S (TK) & \\
\hline Penghasilan dan Pemotongan PPh Pasal 21 & $\mathbf{R p}$ \\
\hline Penghasilan Bruto & 75.000 .000 \\
\hline Pengurangan: & \\
\hline BPJS $1 \%$ & 750.000 \\
\hline Iuran Pensiun 2\% & 1.500 .000 \\
\hline Biaya Jabatan 5\% & 3.750 .000 \\
\hline Jumlah Pengurangan & 6.000 .000 \\
\hline Jumlah Penghasilan Neto (1) & 69.000 .000 \\
\hline Penghasilan Tidak Kena Pajak: & \\
\hline Wajib pajak orang pribadi & 54.000 .000 \\
\hline Penghasilan Kena Pajak & 15.000 .000 \\
\hline PPh Pasal 21 atas PKP setahun & 750.000 \\
\hline ?h Pasal 21 sebulan & 62.500 \\
\hline
\end{tabular}

Sumber: Data SPT Tahunan PT. Air Manado 2017

Hasil perhitungan Pajak Penghasilan Pasal 21 diatas pada tabel 6 bisa dilihat bahwa penghasilan neto Bapak J.V.S sebesar Rp. 69.000.000 setahun adalah total seluruh penghasilan dan tunjangan-tunjangan yang dikurangi iuran wajib pegawai, kemudian penghasilan tersebut dikurangi PTKP sehingga menghasilkan Penghasilan Kena Pajak (PKP). PKP tersebut kemudian dikalikan dengan tarif PPh Pasal 21 sebesar 5\% dan akan mendapatkan hasil untuk PKP setahun dan hasilnya kemudian dibagi lagi 12 bulan agar bisa mendapatkan jumlah Pajak Penghasilan Pasal 21 sebulan. 


\begin{tabular}{lr}
\hline 4. Nama : W.N (K/0) & \multicolumn{1}{c}{ Rp } \\
\hline \multicolumn{1}{c}{ Penghasilan dan Pemotongan PPh Pasal 21 } & 60.000 .000 \\
\hline Penghasilan Bruto & 600.000 \\
Pengurangan: & 1.200 .000 \\
BPJS 1\% & 3.000 .000 \\
Iuran Pensiun 2\% & 4.800 .000 \\
Biaya Jabatan 5\% & 55.200 .000 \\
Jumlah Pengurangan & \\
Jumlah Penghasilan Neto (1) & \\
\cline { 2 - 2 } Penghasilan Tidak Kena Pajak: & 54.000 .000 \\
Wajib pajak orang pribadi & 4.500 .000 \\
Wajib Pajak Kawin & 58.500 .000 \\
Penghasilan Kena Pajak & 3.300 .000 \\
PPh Pasal 21 atas PKP setahun & 165.000 \\
PPh Pasal 21 sebulan & 13.750 \\
\hline Sumber: Data SPT Tahuman PT. Air Manado 2017
\end{tabular}

Sumber: Data SPT Tahunan PT. Air Manado 2017

Berdasarkan hasil perhitungan Pajak Penghasilan PPh Pasal 21 diatas pada tabel 7 dapat dilihat bahwa Penghasilan Neto Ibu W.N sebesar Rp. 55.200.000 setahun adalah total seluruh penghasilan dan tunjangan yang dikurangi iuran wajib pegawai, kemudian penghasilan tersebut dikurangi PTKP sehingga menghasilkan Penghasilan Kena Pajak (PKP). PKP tersebut kemudian dikalikan dengan tariff $\mathrm{PPh}$ Pasal 21 sebesar 5\% dan akan mendapatkan hasil untuk PKP setahun dan hasilnya kemudian dibagi lagi 12 bulan dengan tujuan untuk mendapatkan jumlah PPh Pasal 21 sebulan.

\begin{tabular}{|c|c|}
\hline 5. Nama : S.B (K/2) & \\
\hline Penghasilan dan Pemotongan PPh Pasal 21 & $\mathbf{R p}$ \\
\hline Penghasilan Bruto & 50.000 .000 \\
\hline Pengurangan: & \\
\hline Jumlah Pengurangan & 4.000 .000 \\
\hline Jumlah Penghasilan Neto (1) & 46.000 .000 \\
\hline Penghasilan Tidak Kena Pajak: & \\
\hline Wajib pajak orang pribadi & 67.500 .000 \\
\hline Penghasilan Kena Pajak (1-2) & NIHIL \\
\hline
\end{tabular}

\section{Sumber: Data SPT Tahunan PT. Air Manado 2017}

Berdasarkan hasil perhitungan sebelumnya Pajak Penghasilan Pasal 21 diatas pada tabel 8 bisa dilihat juga bahwa penghasilan neto Ibu S.B sebesar Rp. 46.000.000 setahun adalah total seluruh penghasilan dan tunjangan yang dikurangi iuran wajib pegawai, kemudian penghasilan tersebut dikurangi PTKP sehingga menghasilkan Penghasilan Kena Pajak (PKP).

\subsection{Pembahasan}

Analisis Objek Pajak Penghasilan 21. Berdasarkan Peraturan Direktorat Jenderal Pajak Nomor: PER-16/PJ/2016 yaitu penghasilan yang dibayarkan kepada karyawan, berupa:

1. Penghasilan yang bersifat teratur maupun tidak teratur yang diterima oleh pegawai/karyawan tetap

2. Penghasilan yang diterima penerima pensiun secara teratur

3. Penghasilan berupa uang pesangon yang pembayarannya melewati jangka waktu 2 tahun sejak pegawai/karyawan berhenti bekerja

4. Penghasilan tidak tetap atau tenaga kerja harian lepas berupa upah harian, mingguan atau setahun yang dibayarkan secara bulanan 
Analisis Perhitungan Pajak Penghasilan Pasal 21. Adalah : "didalam menghitung Pajak Penghasilan Pasal 21 atas karyawan tetap, terlebih dahulu dihitung seluruh penghasilan bruto yang diterima karyawan tetap pada PT. Air Manado selama sebulan gaji dan segala jenis tunjangan dan pembayaran lainnya".

Analisis Pemotongan PPh Pasal 21. Pemotongan PPh Pasal 21 karyawan tetap pada "PT. Air Manado dilakukan langsung oleh bendahara dan kemudian juga dilaporkan langsung kepada KPPN, sehingga KPPN bisa memotong langsung Pajak Penghasilan Pasal 21 atas penghasilan karyawan tersebut. Penghasilan yang dipotong tersebut kemudian disetorkan langsung ke Kantor Perbendaharaan Negara (KPN) dan selanjutnya akan disetorkan ke rekening Direktorat Jenderal Pajak. KPN membayar setoran pajak setiap bulan pada tanggal 10 bulan berikutnya, misalnya setoran pajak bulan april 2016 dibayarkan pada tanggal 10 bulan mei 2016"

\section{KESIMPULAN DAN SARAN}

\subsection{Kesimpulan}

Setelah menganalisis dan melihat data-data dan keterangan yang diperoleh dari segi perhitungan Pajak Penghasilan Pasal 21 yang dilakukan oleh PT. Air Manado telah sesuai dengan perundang-undangan perpajakan terbaru yakni Peraturan Jenderal Pajak No. PER16/PJ/2016 untuk perhitungan PPh Pasal 21.

\subsection{Saran}

Dari kesimpulan sebelumnya, maka saran yang dapat peneliti berikan untuk PT. Air Manado adalah sebagai berikut:

1. Disarankan untuk merekrut kembali karyawan yang paham akan tatacara perhitungan dan pemotongan Pajak Penghasilan Pasal 21, sehingga PT. Air Manado akan lebih memahami pemungutan pajak yang berlaku sesuai peraturan dan sering juga mengikuti kegiatan yang berhubungan dengan perpajakan dan informasi lebih dalam mengenai peraturan perpajakan terbaru lebih khususnya menyangkut Pajak Penghasilan Pasal 21 dan pajak yang berlaku dalam PT. Air Manado.

2. Terus meng-update sistem terbaru dan bagian administrasi akuntansi perlu memperbaharui setiap peraturan perundangan yang baru mengenai penunjangan dalam proses perhitungan SPT pajak penghasilan pasal 21.

\section{DAFTAR PUSTAKA}

Diana Sari, S. M. 2013. Konseps Dasar Perpajakan Pusat dan Daerah. Bandung: PT Refika Aditama

Kieso,D.E, Weygandt,J.J, \& Warfied, T.D (2011). Intermedite Accounting Volume I IFRS Edition. United states of Amerika: Wiley

Mardiasmo, 2011. Perpajakan (Edisi Revisi Tahun 2011), Yogyakarta: Andi

Mardiasmo, 2013. Perpajakan Edisi Revisi. Yogyakarta: Andi

Mardiasmo, 2017. Perpajakan Edisi Revisi. Yogyakarta: Andi

Munawir S, 2012. Analisis Informasi Keuangan Liberty. Yogyakarta

Peraturan Direktur Jenderal Pajak Nomor PER-32/PJ/20115 Pasal 24 Ayat (1) tentang Setiap Masa Wajib Disetor Ke Kantor Pajak atau Bank yang ditunjuk oleh Menteri Keuangan

Peraturan Direktur Jenderal Nomor PER-16/PJ/2016 tentang Pedoman Teknis Cara Pemotongan, penyetoran, dan Pelaporan Pajak Penghasilan Pasal 21 dan/atau Pajak Penghasilan Pasal 26 sehubungan dengan Pekerjaan, Jasa dan Kegiataan Orang pribadi 
Peraturan Menteri Keuangan Republik Indonesia 162/PMK.011/2012 tanggal 22 Oktober 2012 tentang Penyesuaian Besarnya Penghasilan Tidak Kena Pajak

PMK/250/PMK.03/2008 tentang biaya jabatan atau biaya pensiun yang dapat dikurangi dari penghasilan bruto pegawai tetap atau pensiunan

Pura, R. 2013. Pengantar Akuntansi 1 Pendekatan Siklus Akuntansi. Makassar: Erlangga

Republik Indonesia, 2008. Undang-Undang Akuntansi Nomor 7 Tahun 1983 sebagaiamana yang telah diubah dengan Undang-Undang Nomor 36 Tahun 2008 Tentang Pajak Penghasilan

Republik Indonesia, 2007. Undang Undang Nomor 28 Tahun 2007 tentang Ketentuan Umum dan Tata cara Perpajakan Pasal 1 Aayat 2 Pengertian Wajib Pajak

Winesthy Anasthazia H. Alfons, 2018. Analisis Penerapan Pajak Penghasilan Pasal 21 pada CV Unggul Abadi di Manado 